\title{
Microsatellite genetic differentiation among populations of the Trinidadian guppy
}

\author{
HY Suk and BD Neff \\ Department of Biology, University of Western Ontario, London, Ontario, Canada
}

\begin{abstract}
Insight into the processes of evolutionary change can be obtained by studying the distribution of genetic diversity among populations. Such diversity can be shaped by historical colonization events, population connectivity and adaptation to local selection pressures. Here we examine genetic differentiation of Trinidadian guppies, Poecilia reticulata, by genotyping 373 individuals from 15 populations located in three drainages (northern coast, Caroni and Oropouche) with 7 microsatellite loci. Our data provide little evidence to support previous claims of two major genetic lineages of guppies in northern Trinidad but instead suggest a more complex pattern of gene flow among populations from different drainages. First, some of the populations in the Caroni drainage show genetic signatures similar to those in the Oropouche drainage. Second, the populations in the northern coast are all highly differentiated
\end{abstract}

from those in either the Caroni or Oropouche drainages Despite differing selection regimes owing to predation pressure, populations from upstream and downstream locales typically cluster together, albeit upstream populations consistently have less genetic variability than the corresponding downstream population. There is, however, no overall pattern of isolation by distance. We also find evidence that an artificially transplanted population from the Caroni drainage is successfully invading into other populations within the Oropouche system. Our analysis details the genetic and phylogeographic structure of Trinidadian guppies in the northern range and provides insight into evolutionary processes at different timescales that have shaped genetic heterogeneity in this fish. Heredity (2009) 102, 425-434; doi:10.1038/hdy.2009.7; published online 18 February 2009

Keywords: $F_{\mathrm{ST}}$; genetic structure; guppies; landscape genetics; microsatellites; phylogeography

\section{Introduction}

Historical patterns of dispersal and geographic isolation have been considered key components in shaping genetic diversity across landscapes (Templeton, 1998; Avise, 2000; Coyne and Orr, 2004). By studying the distribution of genetic diversity, insight may be gained into the processes of microevolutionary change. Freshwater systems provide an exceptional opportunity to study such diversity, in part because drainage structure can restrict gene flow among populations and preserve historical imprints of colonization events. Indeed, the high level of genetic subdivision among populations of many freshwater fishes has often been attributed to the isolating effects of drainage structure (Bermingham and Martin, 1998; Lovejoy and de Araújo, 2000; Sivasundar et al., 2001; for an exception see Hernandez-Martich and Smith, 1990). In contrast, populations of marine or estuarine fishes generally exhibit less differentiation, probably from greater dispersal and more extensive gene flow (reviewed by Ward et al., 1994; DeWoody and Avise, 2000).

Two additional processes may influence gene flow among populations within drainages. The first involves

Correspondence: Professor BD Neff, Department of Biology, University of Western Ontario, 1151 Richmond Street, London, Ontario N6A 5B7, Canada.

E-mail:bneff@uwo.ca

Received 14 May 2008; revised 27 November 2008; accepted 12

December 2008; published online 18 February 2009 topographical features including water connectivity and barriers that can affect contemporary dispersal (Castric et al., 2001; Crispo et al., 2006; Caldera and Bolnick, 2008). The second involves adaptive divergence under variable selection pressures whereby dispersers or hybrids tend to have lower fitness than residents and gene flow between ecological environments can thus be impeded (Lu and Bernatchez, 1999; Ogden and Thorpe, 2002; Rundle, 2002; reviewed by Schluter, 2000; Hendry, 2004). Yet, assessing the contribution of these various processes to intraspecific genetic structure remains a major challenge in population biology (Rundle and Nosil, 2005; Crispo et al., 2006; Nosil and Crespi, 2006).

The guppy (Poecilia reticulata) provides a model system for investigating the contributions of colonization, connectivity and adaptation to population genetic differentiation. The guppy is a live-bearing fish native to northeast South America (Venezuela, Guyana and Suriname) and Trinidad and Tobago (Rosen and Bailey, 1963; Farr, 1975). In northern Trinidad, the species has been intensively studied at a geographic scale with a majority of studies focusing on the impact that predation and other ecological factors have had on the evolution of morphology, behavior and life history (for reviews see Endler, 1995; Houde, 1997; Magurran, 2005). For example, many upstream (headwater) populations are isolated from downstream populations by impassable waterfalls that preclude large piscivorous fishes from reaching the upstream locales (Endler, 1995). Reflecting this selective dichotomy, upper and lower populations within rivers 


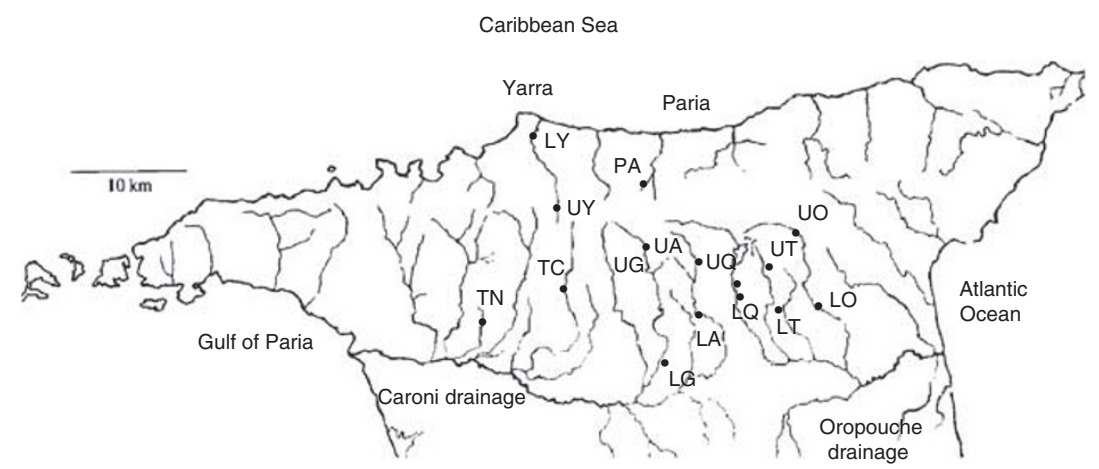

Figure 1 Location of the 15 guppy (Poecilia reticulata) populations sampling sites in northern Trinidad. Populations comprise, from the northern coast: lower Yarra (LY), upper Yarra (UY) and Paria (PA); from the Oropouche drainage: lower Quare (LQ), upper Quare, lower Oropouche (LO), upper Oropouche (UO), lower Turure (LT) and upper Turure (UT); and from the Caroni drainage: lower Guanapo (LG), upper Guanapo (UG), lower Aripo (LA), upper Aripo (UA), Tunapuna (TN) and Tacarigua (TC).

show consistent differences in a broad range of adaptive traits including color (Endler, 1983; Godin and McDonough, 2003), behavior (Magurran et al., 1992; Kelley and Magurran, 2003), and life-history traits (Reznick and Bryga, 1996; Reznick et al., 2001).

Other studies have used genetic markers to directly assess population differentiation. First, studies using allozymes or mtDNA have revealed marked genetic divergence between populations from two major drainages, the Caroni, which drains west into the Gulf of Paria, and the Oropouche, which flows east into the Atlantic Ocean (Figure 1; Carvalho et al., 1991; Shaw et al., 1991, 1994; Fajen and Breden, 1992; Alexander et al., 2006). Differentiation between the two drainages supports the 'two arcs' hypothesis, which asserts that the freshwater fauna in the Caroni (including northernflowing rivers along the northern coast) and Oropouche drainages derive from different ancestral lineages (Boos, 1984). Specifically, during the Pleistocene era, sea levels were up to $130 \mathrm{~m}$ lower than at present (Kenny, 1989) and parts of the Orinoco river system-the major river system running through Venezuela-discharged northward and into the Gulf of Paria, and probably created confluences with the present-day Caroni drainage and several rivers along the northern coast of Trinidad (Ingman et al., 2000; Alexander et al., 2006). Conversely, the Oropouche drainage likely had confluences with a different drainage system on mainland South America and would have been exposed to different colonizing events. Second, a study has provided a detailed analysis of populations from within a single river system, the Marianne (Crispo et al., 2006). This study revealed considerable differentiation among sites within the river and attributed the differentiation to waterfall barriers and isolation by distance. Conversely, local habitat features and predation regime did not appear to account for the differentiation among sites. It is not yet clear, however, if this pattern holds up across a broader landscape involving multiple rivers and drainages.

Here we use microsatellite DNA markers to examine genetic diversity of guppies from northern Trinidad. We examine a total of 15 populations that cover a range of landscape features, degrees of connectivity and predation regimes within northern Trinidad. We compare our data to previous analyses based on allozymes and mtDNA, and use the patterns of genetic differentiation to discuss the potential colonization history. We anticipated that there would be strong genetic differentiation between populations from the Caroni and Oropouche drainages, but not between those from the Caroni drainage and the rivers on the northern coast. We also expected that local adaptation and waterfall barriers would lead to differentiation between upstream and downstream populations within rivers except for those from the Oropouche river, which lacks barriers (Endler, 1995). Finally, we anticipated that there would be an overall pattern of isolation by distance as has been noted previously within a single river system (Crispo et al., 2006).

\section{Materials and methods}

\section{Sample collection}

Guppies were collected using seine and dip nets during May to June 2005 and May to September 2006 from 15 sites across northern Trinidad (Figure 1). Entire body tissues of all individuals were preserved in $95 \%$ ethanol, and a total of 373 fishes were genotyped. Populations were classified as northern coast ( $n=98$ individuals from 3 populations), Oropouche drainage ( $n=157$ individuals from 6 populations) and Caroni drainage $(n=118$ individuals from 6 populations) according to geographic location (Table 1; Figure 1). Guppies were sampled from both upstream (upper populations) and downstream (lower populations) locales in six rivers, Aripo, Guanapo, Yarra, Turure, Quare and Oropouche, and from single sites in three additional rivers, Paria, Tacarigua and Tunapuna (Figure 1). One of the populations represents a transplant from another site; in 1957, 200 guppies from the lower Guanapo were introduced by CP Haskins into an area of the headwaters of the Turure river (upper Turure), which was previously devoid of guppies (Magurran, 2005).

\section{Microsatellite genotyping}

We used the Wizard Genomic DNA purification kit (Promega, Madison, WI, USA) to extract genomic DNA from the tail fin of each fish. For genotyping, we used three previously published dinucleotide microsatellite loci (Pr39, Pr92 and Pr171; Becher et al., 2002) and four tetranucleotide microsatellite loci (Pre8, Pre9, Pre15 and Pre26; Paterson et al., 2005; Table 2). The forward primers were fluorescently labeled (Sigma-Genosys, The wood- 
Table 1 List of the 15 guppy (Poecilia reticulata) populations from northern Trinidad

\begin{tabular}{|c|c|c|c|c|c|c|c|}
\hline Drainage & Population & Location & Predation $^{\mathrm{a}}$ & $\mathrm{n}$ & A & $\mathrm{H}_{O}$ & $\mathrm{H}_{E}$ \\
\hline \multirow[t]{3}{*}{ Northern } & Lower Yarra (LY) & PS $807948^{\mathrm{b}}$ & High & 20 & 6.6 & 0.471 & 0.576 \\
\hline & Upper Yarra (UY) & PS $833876^{\mathrm{b}}$ & Low & 19 & 2.3 & 0.203 & 0.246 \\
\hline & Paria (PA) & $\begin{array}{l}\mathrm{N} 10^{\circ} 44.700^{\prime} \\
\mathrm{W}^{\prime} 61^{\circ} 15.704^{\prime}\end{array}$ & Low & 59 & 4 & 0.341 & 0.325 \\
\hline \multirow[t]{6}{*}{ Oropouche } & Lower Quare (LQ) & $\begin{array}{l}\text { N10 }{ }^{\circ} 40.418^{\prime} \\
\text { W061 }^{\circ} 11.833^{\prime}\end{array}$ & High & 38 & 9.9 & 0.620 & 0.676 \\
\hline & Upper Quare (UQ) & $\begin{array}{l}\text { N10 } 40.553^{\prime} \\
\text { W061 }^{\circ} 11.792^{\prime}\end{array}$ & Low & 39 & 9.7 & 0.554 & 0.603 \\
\hline & Lower Oropouche (LO) & $\begin{array}{l}\mathrm{N} 10^{\circ} 39.570^{\prime} \\
\mathrm{W}^{\prime} 61^{\circ} 07.868^{\prime}\end{array}$ & High & 20 & 10 & 0.575 & 0.702 \\
\hline & Upper Oropouche (UO) & $\begin{array}{l}\text { N10 } 43.060^{\prime} \\
\text { W061 }^{\circ} 08.800^{\prime}\end{array}$ & High & 20 & 9.7 & 0.585 & 0.685 \\
\hline & Lower Turure (LT) & $\begin{array}{l}\text { N10 } 39.394^{\prime} \\
\text { W061 }^{\circ} 10.059^{\prime}\end{array}$ & High & 21 & 8.6 & 0.544 & 0.654 \\
\hline & Upper Turure (UT) & $\begin{array}{l}\text { N10 } 40.775^{\prime} \\
\text { W06 }^{\circ} 10.002^{\prime}\end{array}$ & Low & 19 & 6.6 & 0.632 & 0.648 \\
\hline \multirow[t]{6}{*}{ Caroni } & Lower Guanapo (LG) & PS $909744^{\mathrm{b}}$ & High & 19 & 8.3 & 0.491 & 0.712 \\
\hline & Upper Guanapo (UG) & PS $893848^{\mathrm{b}}$ & Low & 19 & 1.9 & 0.120 & 0.127 \\
\hline & Lower Aripo (LA) & $\begin{array}{l}\text { N10 } 39.036^{\prime} \\
W^{\circ} 61^{\circ} 13.380^{\prime}\end{array}$ & High & 21 & 8.6 & 0.565 & 0.684 \\
\hline & Upper Aripo (UA) & $\begin{array}{l}\text { N10 } 41.743^{\prime} \\
W^{\prime} 061^{\circ} 12.406^{\prime}\end{array}$ & Low & 19 & 4.4 & 0.405 & 0.381 \\
\hline & Tunapuna (TN) & PS $759797^{\mathrm{b}}$ & Low & 20 & 5.1 & 0.546 & 0.625 \\
\hline & Lower Tacarigua (TC) & $\begin{array}{l}\text { N10 } 40.736^{\prime} \\
\text { W061 }^{\circ} 19.168^{\prime}\end{array}$ & High & 20 & 9.3 & 0.508 & 0.673 \\
\hline
\end{tabular}

Data comprise drainage, population, collection location, predation regime, total number of individuals analyzed $(n)$, mean number of alleles per locus $(A)$ and mean observed $\left(H_{\mathrm{O}}\right)$ and expected heterozygosity $\left(H_{\mathrm{E}}\right)$.

${ }^{a}$ Predation pressure from Endler and Houde (1995) and field observations by the authors.

${ }^{b}$ Map grid references (PS) were used due to poor signal reception for GPS coordinates.

Table 2 Summary of the seven microsatellite loci used to study the genetic differentiation among 15 guppy (Poecilia reticulata) populations from northern Trinidad

\begin{tabular}{lcrcclcc}
\hline Loci & Size range $(b p)$ & $\mathrm{A}$ & $\mathrm{H}_{O}$ & $\mathrm{H}_{E}$ & $\mathrm{~F}_{I S}$ & $\mathrm{~F}_{S T}$ & $\mathrm{R}_{S T}$ \\
\hline Pre8 & $167-388$ & 39 & 0.520 & 0.725 & $0.160^{* * *}$ & 0.245 & 0.351 \\
Pre9 & $154-258$ & 24 & 0.725 & 0.736 & 0.04 & 0.172 & 0.276 \\
Pre15 & $124-378$ & 44 & 0.834 & 0.855 & 0.079 & 0.098 & 0.544 \\
Pre26 & $129-146$ & 5 & 0.034 & 0.037 & 0.047 & 0.021 & 0.042 \\
Pr39 & $149-200$ & 16 & 0.529 & 0.563 & 0.092 & 0.34 & 0.262 \\
Pr92 & $148-168$ & 9 & 0.406 & 0.457 & 0.081 & 0.398 & 0.301 \\
Pr171 & $244-356$ & 25 & 0.331 & 0.506 & $0.222^{* * *}$ & 0.481 & 0.596
\end{tabular}

Data include allele size range in base pairs, total number of alleles $(A)$ across all populations, mean observed $\left(H_{\mathrm{O}}\right)$ and expected heterozygosity $\left(H_{\mathrm{E}}\right), F_{\mathrm{IS}}, F_{\mathrm{ST}}$ and $R_{\mathrm{ST}}$.

***P<0.001.

lands, TX, USA). We used a T1 Thermocycler (Whatman Biometra) or PTC-200 (MJ Research) to amplify the microsatellites with the following program: $94{ }^{\circ} \mathrm{C}$ for $10 \mathrm{~min}, 35$ cycles of $30 \mathrm{~s}$ at $94^{\circ} \mathrm{C}, 30 \mathrm{~s}$ at $58^{\circ} \mathrm{C}$ (for Pr39, Pr92, Pr171 and Pre9) and $61^{\circ} \mathrm{C}$ (for Pre8, Pre15 and Pre26), $30 \mathrm{~s}$ at $72{ }^{\circ} \mathrm{C}$ and final elongation at $72{ }^{\circ} \mathrm{C}$ for $10 \mathrm{~min}$. Each $10 \mu \mathrm{l}$ PCR reaction contained $\sim 75 \mathrm{ng}$ of total DNA, $3 \mathrm{mM} \mathrm{MgCl}_{2}, 1 \times$ PCR buffer (Invitrogen Life Technologies, Carlsbad, CA, USA), $0.25 \mathrm{mM}$ of each deoxynucleotide (Sigma-Aldrich, St Louis, MO, USA), 0.25 units Taq DNA polymerase (Invitrogen Life Technologies) and $0.25 \mu \mathrm{M}$ of each forward and reverse primer (Invitrogen Life Technologies). PCR product was run out following the standard protocol for the CEQ 8000 Genetic Analysis System (Beckman Coulter).
Genetic diversity

Genetic diversity was quantified by the number of alleles per locus, observed heterozygosity $H_{\mathrm{O}}$ and expected heterozygosity $H_{\mathrm{E}}$ (Nei, 1987) using GENETIX 4.0 (Belkhir et al., 2000). Given the variation in sample sizes across the collection sites, within-population genetic diversity was also assessed using the allelic richness index of El Mousadik and Petit (1996), which was calculated using FSTAT, version 2.9.3.2 (Goudet, 2001). Deviations from Hardy-Weinberg equilibrium (HWE) were tested for each locus-population combination using the GENEPOP 3.1d package (Raymond and Rousset, 1995) with the exact test based on a Markov chain method (Guo and Thompson, 1992). For tests over all loci, the significance of departures from expected HWE genotype frequencies was assessed. Linkage disequilibrium between pairs of loci was estimated according to Weir (1979) and tested on a contingency table under the null hypothesis of independence.

\section{Population structure}

To examine the extent of genetic differentiation and structuring, multiple approaches were used. The statistics make different assumptions about the mode of mutation at microsatellites and are derived from either the infinite alleles model (IAM) or the stepwise mutation model (SMM). Although statistics based on the SMM typically suffer high sampling variances, those based on the IAM can underestimate differentiation among highly structured populations in which mutation rates are greater than migration rates (Balloux and Lugon-Moulin, 
2002). As a conservative approach, both families of statistics are used in the present study. We estimated global $F_{\mathrm{ST}}$ (Weir and Cockerham, 1984) and $R_{\mathrm{ST}}$ (Rousset, 1996), as well as pairwise- $F_{\mathrm{ST}}$ (Weir and Cockerham, 1984) and pairwise- $R_{\mathrm{ST}}$ (Michalakis and Excoffier, 1996) using GENEPOP. We then used a randomization procedure of allele sizes (SPAGeDi 1.1; Hardy and Vekemans, 2002), whereby the different allele sizes observed at a locus for a given data set are randomly permuted 2000 times to test the null hypothesis that allele sizes from stepwise mutation do not contribute to population differentiation (Hardy et al., 2003). If allele sizes contribute to differentiation, the $R_{\mathrm{ST}}$ computed after the allele size permutation (hereafter called $p R_{\mathrm{ST}}$ ) would depend on allele identity/nonidentity and hence have a smaller expectation than the value computed before randomization $\left(R_{\mathrm{ST}}>p R_{\mathrm{ST}}=F_{\mathrm{ST}}\right.$; Hardy et al., 2003).

An analysis of potential differentiation by distance of the guppy populations was performed by estimating the correlation coefficient of $F_{\mathrm{ST}} /\left(1-F_{\mathrm{ST}}\right)$ and geographical distance between populations. Geographic distance along the length of the river (river distance + coastal contour) and Euclidean distance (straight line) were measured from a Trinidad and Tobago map (scale 1:150000; published by Rough Guides). Significance of the relationship was evaluated with 100000 permutations in a Mantel test that was performed with the program TFPGA, version 1.3 (Miller, 1997). Hierarchical genetic structuring was analyzed by assessing the relative contributions of among-drainage, among-population and within-population components using an analysis of molecular variance (AMOVA, Excoffier et al., 1992). The AMOVA was performed using the program Arlequin 2.0 (Schneider et al., 1997)> and was carried out with both IAM- and SMM-based distance measures; the significance of each hierarchical level was tested with 1000 permutations.

\section{Phylogenetic relationships}

Genetic divergence among populations was first quantified by Cavalli-Sforza and Edwards' (1967) chord distance $\left(D_{\mathrm{CE}}\right)$, which makes no assumption regarding constant population size or mutation rates among loci. The magnitude of this distance is not proportional to evolutionary time, but its use generally leads to a higher probability of depicting the correct tree topology among closely related populations under either the IAM or the SMM assumptions (Nei and Takezaki, 1996; Takezaki and Nei, 1996). $D_{\mathrm{CE}}$ distances were computed using the GeneDist program included in the PHYLIP program, version 3.6 (Felsenstein, 2004). We then computed $(\delta \mu)^{2}$ pairwise population distances of Goldstein et al. (1995) using MsatBootstrap 1.1 (computations carried out with MsatBootstrap 1.1, available from http://www.helsinki. $\mathrm{fi} / \sim$ primmer). The $(\delta \mu)^{2}$ statistic takes into account deviations of allele size variance from theoretical expectations under the SMM. Contrary to other SMMbased estimators, $(\delta \mu)^{2}$ has the advantage of being independent of population size (under mutation-drift equilibrium), and of allowing direct estimation of time since population divergence when mutation rates can be approximated (Goldstein et al., 1995). $(\delta \mu)^{2}$ has also been shown to be more appropriate than other methods for approximating actual branch lengths (Takezaki and Nei, 1996). Pairwise distances obtained from $D_{\mathrm{CE}}$ and $(\delta \mu)^{2}$ estimates were independently used to construct population trees using the neighbor-joining (NJ) algorithm (Saitou and Nei, 1987) available in PHYLIP 3.67 (Supplementary Figure 1S (a) and (b) in Supplementary Materials). Confidence estimates on tree topologies obtained from observed distance values were estimated by the percentage of 1000 bootstraps performed by resampling loci and were compiled using the Consense program of PHYLIP. Finally, a population tree was reconstructed using a combined approach. In this tree, $D_{\mathrm{CE}}$ topology was imposed by the user tree option available in PHYLIP (in the Fitch program), and the Cavalli-Sforza and Edwards (1967) least-squares method was used to estimate branch lengths from the $(\delta \mu)^{2}$ distance matrix.

The population structure was further analyzed in a Bayesian framework. An individual-level clustering method was applied to detect genetically divergent clusters without a priori assumptions of population structure. This approach can detect hidden population structure within samples or among geographical sampling locations and can group nondifferentiated sampling units (Corander et al., 2003). We used the BAPS 2 program with three iterations run for each value of $K$ (the putative number of clusters) using the admixture model with Monte Carlo Markov chain values of 100000 each, and values of $K=1-30$ (Corander et al., 2003). The number of significant clusters was determined from the log-likelihood ratios based on when they reached a plateau (Lindholm et al., 2005; Crispo et al., 2006).

\section{Results}

\section{Genetic diversity}

Extensive genetic polymorphism was detected at the seven microsatellite loci studied (Tables 1 and 2); for example, across the populations, the observed number of alleles at a locus ranged from 5 to 44 and $H_{\mathrm{E}}$ ranged from 0.037 to 0.855 . Within rivers, there were consistent differences between populations with downstream (lower) populations displaying greater variability than upstream (upper) populations (Table 1). These differences were significant for allelic richness (permutation test, $P=0.042)$ and both heterozygosity measures $\left(H_{\mathrm{O}}\right.$, $\left.P=0.002 ; H_{\mathrm{E}}, P=0.019\right)$. At the regional scale, levels of genetic variation were significantly different in all three drainages (allelic richness, $P=0.049 ; H_{\mathrm{O}}, P=0.039 ; H_{\mathrm{E}}$, $P=0.045$; Table 3).

No significant departure from HWE was detected at the population level. At the locus level, two loci deviated significantly from the expectation (Table 2) due to significant heterozygote deficiency in several populations (Pre8 and Pr171; Supplementary Table S1 in Supplementary Materials). Such a result can be expected by sampling error or the presence of null alleles, and thus does not necessarily indicate significant inbreeding or Wahlund effects in the population. Exact tests for genotypic linkage disequilibrium did not reveal any significant effect, which suggests the absence of physical linkage of the loci and of population substructuring within our sampling sites. 


\section{Population structure}

The overall genetic differentiation among populations was substantial with global $F_{\mathrm{ST}}=0.280$. and $R_{\mathrm{ST}}=0.447$ (standardized $G_{\mathrm{ST}}^{\prime}=0.941$; Hedrick, 2005). The differentiation pattern varied significantly among drainages (permutation test, $F_{\mathrm{ST}}, P=0.018 ; R_{\mathrm{ST}}, P=0.007$; Table 3 ). The northern coast and Caroni drainage showed high population subdivision, whereas populations within the Oropouche drainage were less differentiated (Table 3). Within drainages, the Turure populations in the Oropouche drainage appeared to have the genetic signature of the lower Guanapo in the Caroni drainage (Table 4), as may have been expected given the transplant history of these populations. Specifically, outside of the lower Turure, the upper Turure was more similar to the lower Guanapo than any other population in its drainage. Interestingly, the lower Aripo showed higher genetic affinity to populations from the Oropouche drainage than those from its own drainage (Table 4). Within rivers,

Table 3 Summary of six statistics of genetic variability and differentiation for 15 guppy (Poecilia reticulata) populations from northern Trinidad

\begin{tabular}{lccc}
\hline Statistic & Northern coast & Oropouche drainage & Caroni drainage \\
\hline Allelic richness & 3.865 & 7.474 & 5.865 \\
$H_{\mathrm{O}}$ & 0.350 & 0.612 & 0.476 \\
$H_{\mathrm{E}}$ & 0.366 & 0.670 & 0.552 \\
$F_{\mathrm{ST}}$ & 0.525 & 0.099 & 0.295 \\
$R_{\mathrm{ST}}(95 \% \mathrm{CI})$ & 0.598 & 0.184 & 0.399 \\
$p R_{\mathrm{ST}}(0.580$ & 0.082 & 0.229 \\
& $(0.066-0.674)$ & $(0.025-0.164)^{*}$ & $(0.100-0.434)^{*}$ \\
$n$ & $98(3)$ & $157(6)$ & $118(6)$ \\
\hline
\end{tabular}

The populations are divided based on drainage and the statistics comprise allelic richness, observed heterozygosity $\left(H_{\mathrm{o}}\right)$, expected heterozygosity $\left(H_{\mathrm{E}}\right), F_{\mathrm{ST}}, R_{\mathrm{ST}}$ and $p R_{\mathrm{ST}}\left(R_{\mathrm{ST}}\right.$ computed after allele size permutation with the $95 \%$ confidence interval in parentheses). The $n$ provides the number of individuals with populations in parentheses analyzed from each drainage.

${ }^{*} P<0.05$ under the assumption of observed $R_{\mathrm{ST}}>p R_{\mathrm{ST}}$. the genetic differentiation between upper and lower populations varied across drainages. For example, in the Oropouche drainage, upper and lower populations were relatively similar (pairwise- $F_{\mathrm{ST}}=0-0.08$, pairwise$R_{\mathrm{ST}}=0-0.02$ ), whereas those from the Yarra river in the northern coast and those from the rivers in the Caroni drainage were considerably more differentiated (pairwise- $F_{\mathrm{ST}}=0.16-0.41$, pairwise- $R_{\mathrm{ST}}=0.08-0.53$ ).

The hierarchical AMOVA revealed that most of the genetic variance was found among populations within drainages compared to a smaller proportion among drainages or individuals within populations (Table 5). The Mantel test failed to find any correlation of genetic differentiation with geographic distance separating populations ( $F_{\mathrm{ST}}: r=0.015, \quad P=0.602 ; \quad R_{\mathrm{ST}}: r=0.098$, $P=0.240)$ and with Euclidean distance $\left(F_{\mathrm{ST}}: r=0.109\right.$, $P=0.109 ; R_{\mathrm{ST}}: r=0.152, P=0.139$ ).

Overall, multilocus $R_{\mathrm{ST}}$ values were significantly higher than mean permuted $R_{\mathrm{ST}}$ values $\left(R_{\mathrm{ST}}=0.447\right.$, $\left.p R_{\mathrm{ST}}=0.214 ; P=0.001\right)$, suggesting a contribution of stepwise mutations at the microsatellite loci. At a regional level, allele size permutation tests demonstrated

Table 5 Summary of the AMOVA results that partition genetic variation among 15 guppy (Poecilia reticulata) populations from northern Trinidad to three different landscape levels

\begin{tabular}{lcc}
\hline Source of variation & \multicolumn{2}{c}{ Mutation model } \\
\cline { 2 - 3 } & IAM $\left(\mathrm{F}_{S T}\right)$ & $S M M\left(\mathrm{R}_{S T}\right)$ \\
\hline Among drainages & $4.6^{*}$ & $10.6^{*}$ \\
Among populations, within drainages & $25.2^{*}$ & $40.1^{*}$ \\
Among individuals, within populations & $6.7^{*}$ & $12.1^{*}$ \\
Residual & 63.6 & 37.2
\end{tabular}

The levels comprise drainage, populations and individuals and the data are based on seven microsatellite loci and are expressed as a percentage. Two mutation models were considered, the infinite alleles model (IAM) and the stepwise mutation model (SMM). ${ }^{*} P<0.05$.

Table 4 Summary of genetic differentiation parameters for pairwise comparisons of 15 guppy (Poecilia reticulata) populations from northern Trinidad

\begin{tabular}{|c|c|c|c|c|c|c|c|c|c|c|c|c|c|c|c|}
\hline & \multicolumn{3}{|c|}{ Northern } & \multicolumn{6}{|c|}{ Oropouche } & \multicolumn{6}{|c|}{ Caroni } \\
\hline & $L Y$ & $U Y$ & $P A$ & $L Q$ & $U Q$ & $L O$ & UO & $L T$ & $U T$ & $L G$ & $U G$ & $L A$ & $U A$ & $T N$ & $T C$ \\
\hline LY & & 0.53 & 0.51 & 0.20 & 0.19 & 0.20 & 0.19 & 0.22 & 0.25 & 0.20 & 0.40 & 0.21 & 0.15 & 0.46 & 0.40 \\
\hline UY & 0.36 & & 0.80 & 0.80 & 0.71 & 0.77 & 0.78 & 0.79 & 0.79 & 0.76 & 0.92 & 0.79 & 0.83 & 0.82 & 0.75 \\
\hline PA & 0.47 & 0.63 & & 0.47 & 0.40 & 0.48 & 0.45 & 0.69 & 0.67 & 0.60 & 0.86 & 0.48 & 0.48 & 0.80 & 0.69 \\
\hline LQ & 0.18 & 0.38 & 0.38 & & 0.02 & $0.01^{\mathrm{NS}}$ & $0.00^{\mathrm{NS}}$ & 0.39 & 0.34 & 0.24 & 0.68 & 0.03 & 0.04 & 0.61 & 0.47 \\
\hline$\widehat{U Q}$ & 0.24 & 0.43 & 0.44 & 0.08 & & 0.00 & $0.00^{\mathrm{NS}}$ & 0.27 & 0.21 & 0.12 & 0.52 & 0.01 & 0.07 & 0.48 & 0.35 \\
\hline $\mathrm{LO}$ & 0.08 & 0.37 & 0.39 & 0.06 & 0.12 & & $0.00^{\mathrm{NS}}$ & 0.34 & 0.28 & 0.19 & 0.66 & $0.00^{\mathrm{NS}}$ & 0.08 & 0.52 & 0.36 \\
\hline UO & 0.13 & 0.38 & 0.37 & 0.05 & 0.14 & 0.02 & & 0.36 & 0.31 & 0.21 & 0.71 & $0.00^{\mathrm{NS}}$ & 0.05 & 0.54 & 0.39 \\
\hline LT & 0.20 & 0.41 & 0.35 & 0.12 & 0.18 & 0.11 & 0.07 & & 0.02 & $0.04^{\mathrm{NS}}$ & 0.26 & 0.36 & 0.44 & 0.20 & 0.16 \\
\hline UT & 0.18 & 0.42 & 0.37 & 0.13 & 0.17 & 0.10 & 0.08 & $0.00^{\mathrm{NS}}$ & & $0.00^{\mathrm{NS}}$ & 0.32 & 0.31 & 0.43 & 0.25 & 0.12 \\
\hline LG & 0.14 & 0.40 & 0.39 & 0.12 & 0.17 & 0.07 & 0.08 & 0.06 & 0.05 & & 0.36 & 0.21 & 0.31 & 0.28 & 0.15 \\
\hline UG & 0.52 & 0.74 & 0.63 & 0.41 & 0.48 & 0.44 & 0.40 & 0.31 & 0.36 & 0.41 & & 0.71 & 0.85 & 0.57 & 0.40 \\
\hline LA & 0.13 & 0.40 & 0.40 & 0.13 & 0.20 & 0.07 & 0.08 & 0.12 & 0.13 & 0.09 & 0.44 & & 0.08 & 0.54 & 0.39 \\
\hline UA & 0.34 & 0.61 & 0.57 & 0.27 & 0.35 & 0.27 & 0.30 & 0.35 & 0.36 & 0.27 & 0.68 & 0.16 & & 0.64 & 0.48 \\
\hline $\mathrm{TN}$ & 0.20 & 0.43 & 0.46 & 0.21 & 0.26 & 0.17 & 0.20 & 0.19 & 0.19 & 0.15 & 0.50 & 0.17 & 0.35 & & $0.04^{\mathrm{NS}}$ \\
\hline $\mathrm{TC}$ & 0.17 & 0.42 & 0.39 & 0.15 & 0.16 & 0.12 & 0.14 & 0.13 & 0.12 & 0.10 & 0.50 & 0.15 & 0.32 & 0.15 & \\
\hline
\end{tabular}

Estimates of $F_{\mathrm{ST}}$ appear below the diagonal and estimates of $R_{\mathrm{ST}}$ appear above the diagonal. Populations are grouped by drainage. Note: see Table 1 for full names of each population; all comparisons are significantly different from zero $(P<0.05)$ except those denoted by 'NS'. 
that shifts in average allele sizes contributed significantly to population differentiation in the Caroni and Oropouche drainages, but not to those in the northern coast (Table 3). At the locus level, Pre15 (northern coast and Caroni), Pr171 (Oropouche and Caroni) and Pre9 (Caroni) all showed a significant effect of allele sizes $(P<0.05$ for each). No test was done for Pre26 because it contained only 5 alleles across the 15 populations; thus the number of permutation configurations was too low to carry out the test.

\section{Phylogenetic relationships}

The combined tree reconstructed from the $D_{\mathrm{CE}}$ tree topology and branch length estimation from $(\delta \mu)^{2}$ distances is presented in Figure 2. In comparison to the $D_{\mathrm{CE}}$ tree (Supplementary Figure $1 \mathrm{~S}$ in Supplementary Materials), the combined tree showed a substantial reduction in branch lengths among populations within groups relative to those among groups. We thus focused on the combined tree. This tree revealed six major population clusters (Figure 2). Four of the populations

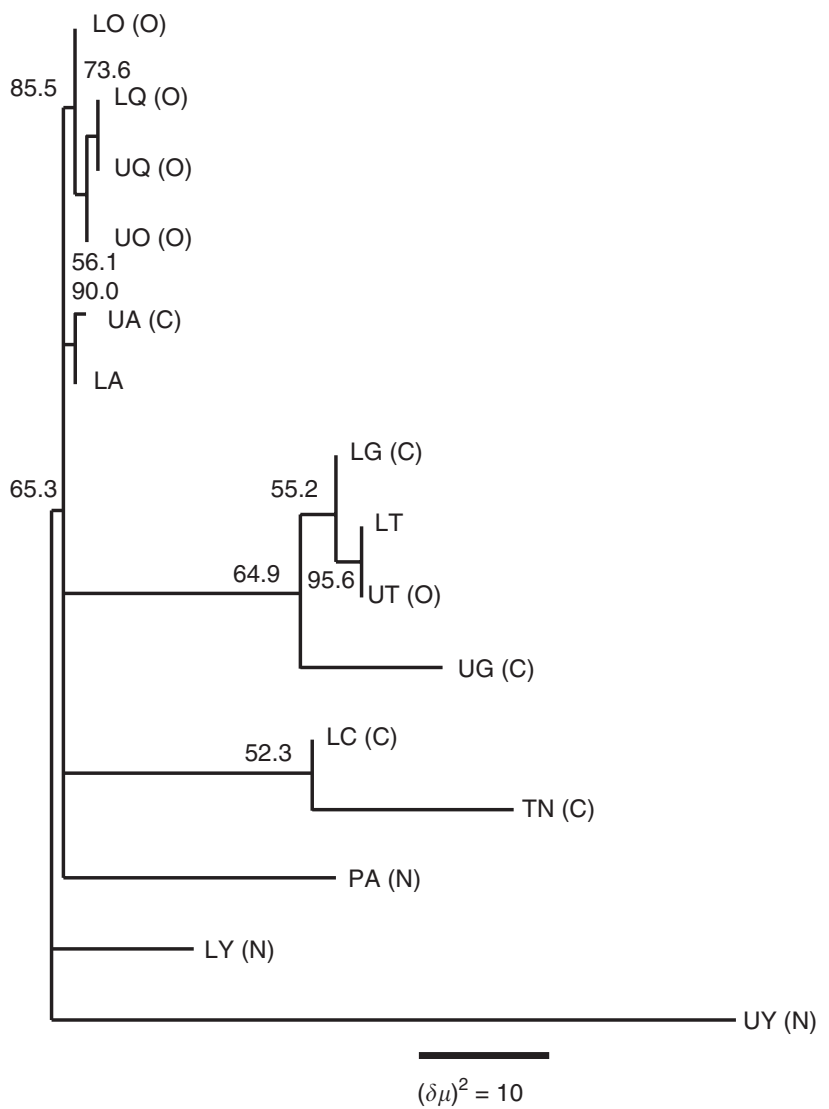

Figure 2 Phylogenetic relationships of the 15 guppy (Poecilia reticulata) populations from northern Trinidad. The tree topology is estimated from Cavalli-Sforza and Edwards' chord distance, whereas the branch lengths were extracted from Goldstein's $(\delta \mu)^{2}$ distance matrix. Bootstrap supports greater than $50 \%$ are indicated. Populations comprise, from the northern coast $(\mathrm{N})$ : lower Yarra (LY), upper Yarra (UY) and Paria (PA); from the Oropouche drainage $(\mathrm{O})$ : lower Quare $(\mathrm{LQ})$, upper Quare, lower Oropouche (LO), upper Oropouche (UO), lower Turure (LT) and upper Turure (UT) and from the Caroni drainage (C): lower Guanapo (LG), upper Guanapo (UG), lower Aripo (LA), upper Aripo (UA), Tunapuna (TN) and Tacarigua (TC). from the Oropouche drainage (LO, UO, LQ and UQ) composed a cluster supported by a bootstrap value of $86 \%$ and the remaining two populations (UT and LT) formed a separate cluster with a bootstrap value of $96 \%$. These latter two populations clustered with the lower Guanapo and then the upper Guanapo from the Caroni drainage. Populations from the Caroni drainage appeared in three distinct clusters; Aripo populations may cluster to four Oropouche drainage populations (LO, $\mathrm{UO}, \mathrm{LQ}$ and UQ) in the NJ tree (Consense program), but this clustering was not considered in the phylogenetic tree (Figure 2) due to the low bootstrap value (38\%). The Paria population in the northern drainage did not cluster with the other two northern populations (LY and UY; Figure 2). These latter observations indicate that within drainage factors affecting genetic divergence have been sufficient to override the effect of historical and geographical features. To examine the effects of potential null alleles and low polymorphism of some loci on the robustness of our results, NJ trees were constructed with the omission of pre8, pre171 or pre 26 ; however, the clustering pattern was consistent with only small changes to the bootstrap values (data available from the authors).

The Bayesian analysis of population structure provided log-likelihood ratios that reached a plateau at $K=7$, indicating that most of the genetic variation was captured in seven genetic clusters. Individuals from the same river generally clustered together (Table 6). About $70 \%(108 / 157)$ of the individuals from the Oropouche drainage were assigned to a single cluster, which was the largest cluster representing 29\% (108/373) of the total number of individuals analyzed. In contrast, populations from the northern coast and Caroni drainage formed two and four major clusters, respectively. In some cases a single individual clustered with river(s) from another drainage. For example, one individual collected from the lower Aripo clustered with those from the Quare and Oropouche rivers. Conceivably this individual was

Table 6 Summary of the Bayesian analysis of population structure for 15 guppy (Poecilia reticulata) populations from northern Trinidad

\begin{tabular}{|c|c|c|c|c|c|c|c|c|c|}
\hline \multirow[t]{2}{*}{ Drainages } & \multirow[t]{2}{*}{ Site } & \multicolumn{7}{|c|}{ Inferred cluster } & \multirow[t]{2}{*}{ Total } \\
\hline & & 1 & 2 & 3 & 4 & 5 & 6 & 7 & \\
\hline \multirow[t]{3}{*}{ Northern } & LY & 19 & & & & 1 & & & 20 \\
\hline & UY & 19 & & & & & & & 19 \\
\hline & PA & & & & & & & 59 & 59 \\
\hline \multirow{6}{*}{ Oropouche } & LO & 1 & 16 & 1 & 2 & & & & 20 \\
\hline & UO & & 17 & 2 & 1 & & & & 20 \\
\hline & LQ & & 37 & 1 & & & & & 38 \\
\hline & UQ & & 38 & 1 & & & & & 3 \\
\hline & LT & & & 21 & & & & & 2 \\
\hline & UT & & & 19 & & & & & 19 \\
\hline \multirow{7}{*}{ Caroni } & LG & & & 19 & & & & & 1 \\
\hline & UG & & & 19 & & & & & \\
\hline & LA & & 1 & 2 & 18 & & & & 2 \\
\hline & UA & & & & 19 & & & & 19 \\
\hline & $\mathrm{TC}$ & & & & & 20 & & & 20 \\
\hline & $\mathrm{TN}$ & & & & & & 20 & & \\
\hline & Total & 39 & 109 & 85 & 40 & 21 & 20 & 59 & 373 \\
\hline
\end{tabular}

The populations are grouped by drainage and the data represent the number of individuals assigned to each cluster.

Note: see Table 1 for full name of each population. 
actually from the Quare or Oropouche river; although representing different drainages, the rivers are proximate to one another based on straight-line distance (see Figure 1). On the other hand, the individual from the lower Oropouche that clustered with the individuals from the Yarra river is unlikely to have come from the Yarra because they are not proximate to one another. Thus, it seems more probable that these individuals were misclassified in the analysis due to, for example, homoplasy of allele identification.

\section{Discussion}

Our analysis of microsatellite variation revealed extensive genetic structuring of guppy populations in northern Trinidad. We found higher levels of genetic diversity and population subdivision than has been previously reported in studies based on allozymes (Carvalho et al., 1991; Shaw et al., 1991, 1992) and mtDNA (Fajen and Breden, 1992; Alexander et al., 2006). Microsatellites are particularly useful in the study of fine-scale genetic structure because of high mutation rates and levels of polymorphism. Indeed, the loci we used averaged 2-10 alleles and displayed mean heterozygosity values of 0.13-0.71 across the 15 populations. The high polymorphism associated with microsatellites, as opposed to allozymes and mtDNA, probably explains the more detailed population structure that we uncovered.

Our data do not provide compelling support for previous claims of two major genetic lineages of guppies in northern Trinidad. Earlier studies postulated that the guppies in northern Trinidad were differentiated between the Caroni and Oropouche drainages, and that the populations from northern rivers clustered with the Caroni drainage (Boos, 1984; Fajen and Breden, 1992; Alexander et al., 2006). These studies suggested that there were two major colonization events associated with the two drainages. Our data, however, suggest a more complex relationship. The 15 populations we studied could be subdivided into 6 major clusters based on an NJ tree approach and 7 clusters based on Bayesian analysis. These clusters did not coincide with drainage. For example, the Aripo populations in the Caroni drainage did not cluster with other populations from the same drainage, but instead clustered more closely with populations from the Quare and Oropouche rivers in the Oropouche drainage. The three populations from the northern coast, Paria, upper Yarra and lower Yarra, formed two separate clusters and were all highly differentiated. Some caution is warranted when interpreting our results because some of our bootstrap values in the NJ tree were low (although many of the patterns were corroborated by the Bayesian analysis). At the least, our analysis with microsatellite loci does not provide support for clustering of populations into two distinct groups or two distinct colonization events of the Caroni and Oropouche drainages.

Our data suggest a complex pattern of gene flow among populations from different drainages. It was surprising that the lower Aripo clustered with populations from the Oropouche and Quare rivers. Aripo is the farthest river in our study from the Quare and Oropouche rivers based on geographic river and coastal contour distance (that is, water connectivity; Figure 1). Conversely, the Aripo river is actually relatively close to the Quare river based on straight-line distance and during the wet season can be as close as $70 \mathrm{~m}$ (Magurran, 2005). It is conceivable that these adjacent rivers were connected before an isostatic rebound or other major environmental event (for example, flooding). Alternatively, some level of gene flow may be facilitated by anthropogenic activities (for example, intentional or unintentional human movement of guppies from one location to another, installation of roadside drainage systems), or perhaps even by avian predators (for example, if a bird caught a guppy in one river and then dropped it in another). On the other hand, studies have indicated that guppies from the Caroni and Oropouche drainages may be in an early stage of postzygotic reproductive isolation (Ludlow and Magurran, 2006; Russell and Magurran, 2006). It is also conceivable that allele homoplasy hindered the phylogenetic signal in our analysis as the Aripo-Oropouche-Quare cluster was not strongly supported with a bootstrap value of only $38 \%$. Size homoplasy may be problematic in conditions where mutation rates are high and population sizes are large, together with strong allele size constraints (Estoup et al., 2002), although it is unclear as to whether these conditions are met in our data set.

The degree of population genetic differentiation varied across the drainages in northern Trinidad and possibly relates to historical events. The populations from the Caroni drainage and the northern coast exhibited a high degree of interpopulation genetic differentiation whereas the populations from the Oropouche drainage showed only weak genetic structuring (Table 4). These differentiation patterns may bear the signature of river drainage formation and colonization dating back some 1.8 million years ago when Trinidad was part of the northeast edge of mainland South America. For example, it is conceivable that, following deglaciation events and the opening of new dispersal routes, the Caroni drainage and northern coast rivers were independently recolonized by several founding populations that were already differentiated before their postglacial dispersal. Conversely, the Oropouche drainage may have been colonized by a single, undifferentiated refugial unit. Alternatively, guppies within the larger Caroni system may have been subdivided for periods of time postglaciation into populations that were isolated by distance or other physical barriers, whereas those in the smaller Oropouche system may have been less physically divided enabling a greater amount of gene flow. Sampling guppy populations from sites in Venezuela could provide insight into these colonization possibilities.

Some of the genetic patterns in the northern Trinidadian guppies are a clear effect of an anthropogenic transplant. We found, as in other studies, that the Turure and Guanapo populations were remarkably similar (also see Shaw et al., 1991, 1992). In 1957 guppies were transplanted from the lower Guanapo to the upper Turure, a region that was previously devoid of guppies (Magurran, 2005). Shaw et al. (1992) showed using allozyme markers that guppies downstream of a waterfall barrier on the Turure river represent an admixture of native and introduced genotypes. More recently, in an intensive study with nuclear and mtDNA markers, Magurran (2005) found that more than $90 \%$ of individuals in the lower Turure had introduced nuclear alleles but interestingly only half of them had the introduced 
mitochondrial haplotype, indicating strong male-biased dispersal. Consistent with these studies, our data indicate that the population from the lower Guanapo is more related to the population from the lower Turure than to the upper Guanapo. Our results suggest that there has been significant downstream gene flow from the transplanted upper Turure population to the lower Turure population. This gene flow may have removed the genetic signature of the original lower Turure population. Thus, it appears that the introduced genes from the lower Guanapo population are invading into the Oropouche system, or at least throughout the Turure river.

Despite the complex pattern of genetic differentiation among guppy populations in northern Trinidad, there were some consistent patterns between upstream and downstream populations. In most cases we found that upper and lower populations within rivers clustered together (Figure 2). Outside of the anthropogenic introduction noted above, the only exception to this pattern was the Oropouche river, where the upper Oropouche population clustered more closely with the Quare river populations than the lower Oropouche population. Interestingly, unlike the other rivers we studied, the Oropouche river is devoid of waterfall barriers that had been implicated in promoting genetic differentiation among populations within a river on the northern coast (Crispo et al., 2006). Thus, we expected the Oropouche populations to cluster closely together. On the other hand, we also found some consistent differences between upstream and downstream populations. For example, upstream populations tended to have less genetic variability than the corresponding downstream population (Table 1). This pattern is consistent with studies in other fishes, including mosquitofish, Gambusia holbrooki (Hernandez-Martich and Smith, 1990); brown trout, Salmo trutta (Hamilton et al., 1989) and brook charr, Salvelinus fontinalis (Castric et al., 2001). The pattern probably reflects more pronounced founder effects and smaller population sizes associated with upstream populations as well as lower immigration due to unidirectional downstream gene flow (Shaw et al., 1991, 1994; Crispo et al., 2006). Other studies have shown consistent differences between upper and lower populations in a range of phenotypic traits including male color pattern, behavior and life history (reviews in Endler, 1995; Houde, 1997; Magurran, 2005). These phenotypic differences in part reflect differential predation pressures from piscivorous fishes that occupy downstream habitats but are excluded from upstream habitats by natural barriers. Thus, although there appears to be at least some gene flow within rivers, there are notable genetic differences particularly at important life-history and behavioral traits. These differences may ultimately lead to reproductive isolation and incipient speciation between upstream and downstream populations (Hendry et al., 2000; Higgie et al., 2000; Rundle et al., 2000).

In conclusion, our analysis with microsatellites provides a finer understanding of the genetic and phylogeographic structure of Trinidadian guppies in the northern range than previous studies. Most likely because of the relatively short temporal timescale and small geographic scales involved in the within-drainage level differentiation, traditional markers such as mtDNA and allozymes have failed to reveal phylogenetic subdivision (also see
Jarne and Lagoda, 1996; Angers and Bernatchez, 1998) and have instead suggested only two refugial populations. Our study on the other hand suggests a more complex pattern of genetic differentiation across the landscape that probably reflects more than two colonization events from isolated refugial populations. The conflicting results between our study and those of previous studies may result from the differential effects of genetic drift and mutation on marker classes. Nevertheless, the data collectively provide complementary information that is useful for investigating how evolutionary processes at different timescales shape patterns of genetic heterogeneity.

\section{Acknowledgements}

Kristin Ambacher, Su Youn Baek, Jon Evans, Bonnie Fraser, Tim Hain, Raj Mahabir, Jinwon Moon, Trevor Pitcher and Indar Ramnarine assisted with field or laboratory work. Melissa Evans, Bonnie Fraser, Shawn Garner, Tim Hain, and four ananymous reviewers provided comments on this paper. This work was funded by the Natural Sciences and Engineering Research Council of Canada, Canadian Foundation for Innovation, Ontario Innovation Trust and the University of Western Ontario.

\section{References}

Alexander HJ, Taylor JS, Wu SS-T, Breden F (2006). Parallel evolution and vicariance in the guppy (Poecilia reticulata) over multiple temporal and spatial scales. Evolution 60: 2352-2369.

Angers B, Bernatchez L (1998). Combined use of SMM and non-SMM methods to infer fine structure and evolutionary history of brook charr (Salvelinus fontinalis, Salmonidae) populations from microsatellites. Mol Biol Evol 15: 43-159.

Avise JC (2000). Phylogeography: The History and Formation of Species. Harvard University Press: Cambridge.

Balloux F, Lugon-Moulin N (2002). The estimation of population differentiation with microsatellite markers. Mol Ecol 11: 155-165.

Becher SA, Russell ST, Magurran AE (2002). Isolation and characterization of polymorphic microsatellites in the Trinidadian guppy (Poecilia reticulata). Mol Ecol Notes 2: 456-458.

Belkhir K, Borsa P, Chikhi L, Goudet J, Bonhomme F (2000). GENETIX 4.0, logiciel sous Windows ${ }^{\mathrm{TM}}$ pour la Génétique des Populations. Laboratoire Génome, Populations, Intéractions. CNRS UPR 9060, Université de Montpellier II: Montpellier (France).

Bermingham E, Martin AP (1998). Comparative mtDNA phylogeography of neotropical freshwater fishes: testing shared history to infer the evolutionary landscape of lower Central America. Mol Ecol 7: 499-517.

Boos HEA (1984). A consideration of the terrestrial reptile fauna on some offshore islands north west of Trinidad. Living World 1983/1984: 19-26.

Caldera EJ, Bolnick DI (2008). Effects of colonization history and landscape structure on genetic variation within and among threespine stickleback (Gasterosteus aculeatus) populations in a single watershed. Evol Ecol Res 10: 575-598.

Carvalho GR, Shaw PW, Magurran AE, Seghers BH (1991). Marked genetic divergence revealed by allozymes among populations of the guppy Poecilia reticulata (Poeciliidae), in Trinidad. Biol J Linn Soc 42: 389-405.

Castric V, Bonney F, Bernatchez L (2001). Landscape structure and hierarchical genetic diversity in the brook charr, Salvelinus fontinalis. Evolution 55: 1016-1028. 
Cavalli-Sforza LL, Edwards AWF (1967). Phylogenetic analysis: models and estimation procedures. Am J Hum Genet 19: 233-257.

Corander J, Walmann P, Sillanpaa MJ (2003). Bayesian analysis of genetic differentiation between populations. Genetics 163: $367-374$.

Coyne JA, Orr HA (2004). Speciation. Sinauer Associates: Sunderland, MA

Crispo E, Bentzen P, Reznick DN, Kinnison MT, Hendry AP (2006). The relative influence of natural selection and geography on gene flow in guppies. Mol Ecol 15: 49-62.

DeWoody JA, Avise JC (2000). Microsatellite variation in marine, freshwater and anadromous fishes compared with other animals. J Fish Biol 56: 461-473.

El Mousadik A, Petit RJ (1996). Chloroplast DNA phylogeography of the argan tree of Morocco. Mol Ecol 5: 547-555.

Endler J, Houde AE (1995). Geographic variation in female preference for male traits in Poecilia reticulata. Evolution 49: 456-468.

Endler JA (1983). Natural and sexual selection on color patterns in poeciliid fishes. Env Biol Fishes 9: 173-190.

Endler JA (1995). Multiple-trait coevolution and environmental gradients in guppies. Trends Ecol Evol 10: 22-29.

Estoup A, Jarne P, Cornuet JM (2002). Homoplasy and mutation model at microsatellite loci and their consequences for population genetics analysis. Mol Ecol 11: 1591-1604.

Excoffier L, Smouse PE, Quattro JM (1992). Analysis of molecular variance inferred from metric distances among DNA haplotypes: application to human mitochondrial DNA restriction data. Genetics 131: 479-491.

Fajen A, Breden F (1992). Mitochondrial DNA sequence variation among natural populations of the Trinidad guppy, Poecilia reticulata. Evolution 46: 1457-1465.

Farr JA (1975). The role of predation in the evolution of natural populations of the guppy Poecilia reticulata (Pisces: Poeciliidae). Evolution 29: 151-158.

Felsenstein J (2004). PHYLIP (Phylogeny Inference Package) version 3.6. Department of Genome Sciences, University of Washington: Seattle, Washington. Distributed by the Author.

Godin J-GJ, McDonough HE (2003). Predator preference for brightly colored males in the guppy: a viability cost for a sexually selected trait. Behav Ecol 14: 194-200.

Goldstein DB, Ruiz Linares A, Cavalli-Sforza LL, Feldman MW (1995). Genetic absolute dating based on microsatellites and the origin of modern humans. Proc Natl Acad Sci USA 92: $6723-6727$

Goudet J (2001). FSTAT, a program to estimate and test gene diversities and fixation indices. Available from http:// www.unil.ch/izea/softwares/fstat.html.

Guo W, Thompson EA (1992). A Monte Carlo method for combined segregation and linkage analysis. Am J Hum Genet 51: 1111-1126.

Hamilton KE, Ferguson A, Taggart JB, Tómasson T, Walker A, Fahy E (1989). Post-glacial colonization of brown trout, Salmo trutta L.: Ldh-5 as a phylogeographic marker locus. J Fish Biol 35: 651-664.

Hardy OJ, Charbonnel N, Freville H, Heuertz M (2003). Microsatellite allele sizes: a simple test to assess their significance on genetic differentiation. Genetics 163: 1467-1482.

Hardy OJ, Vekemans X (2002). SPAGeDi: a versatile computer program to analyse spatial genetic structure at the individual or population levels. Mol Ecol Notes 2: 618-620.

Hedrick PW (2005). A standardized genetic differentiation measures. Evolution 59: 1633-1638.

Hendry AP (2004). Selection against migrants contributes to the rapid-evolution of reproductive isolation. Evol Ecol Res 6: 1219-1236.

Hendry AP, Wenburg JK, Bentzen P, Volk EC, Quinn TP (2000). Rapid evolution of reproductive isolation in the wild: evidence from introduced salmon. Science 290: 516-518.

Hernandez-Martich JD, Smith MH (1990). Patterns of genetic variation in Eastern mosquitofish (Gambusia holbrooki Girard) from the Piedmont and Coastal Plain of three drainages. Copeia 1990: 610-630.

Higgie M, Chenoweth S, Blows MW (2000). Natural selection and the reinforcement of mate recognition. Science 290: 519-521.

Houde AE (1997). Sex, Color and Mate Choice in Guppies. Princeton University Press: Princeton.

Ingman M, Kaessmann K, Pääbo S, Gyllensten U (2000). Mitochondrial genome variation and the origin of modern humans. Nature 408: 708-713.

Jarne P, Lagoda PJL (1996). Microsatellites, from molecules to populations and back. Trends Ecol Evol 11: 424-429.

Kelley JL, Magurran AE (2003). Effects of relaxed predation pressure on visual predator recognition in the guppy. Behav Ecol Sociobiol 54: 225-232.

Kenny JS (1989). Hermatypic scleractinian corals of Trinidad. Stud Fauna Curaçao 123: 83-100.

Lindholm A, Breden $\mathrm{H}$, Alexander $\mathrm{HJ}$, Woon-Khiong $\mathrm{C}$, Thakurta SG, Brooks R (2005). Invasion success and genetic divergence of introduced populations of guppies Poecilia reticulata in Australia. Mol Ecol 14: 3671-3682.

Lovejoy NR, de Araújo MLG (2000). Molecular systematics, biogeography, and population structure of neotropical freshwater needlefishes of the genus Potamorrhaphis. Mol Ecol 9: 259-268.

Lu G, Bernatchez L (1999). Correlated trophic specialization and genetic divergence in sympatric lake whitefish ecotypes (Coregonus clupeaformis): support for the ecological speciation hypothesis. Evolution 53: 1491-1505.

Ludlow AM, Magurran AE (2006). Gametic isolation in guppies (Poecilia reticulata). Proc $R$ Soc London B 273: 2477-2482.

Magurran AE (2005). Evolutionary Ecology: The Trinidadian Guppy. Oxford University Press: Oxford, UK.

Magurran AE, Seghers BH, Carvalho GR, Shaw PW (1992). Behavioural consequences of an artificial introduction of guppies (Poecilia reticulata) in N. Trinidad: evidence for the evolution of anti-predator behaviour in the wild. Proc $R$ Soc London B 248: 117-122.

Michalakis Y, Excoffier L (1996). A generic estimation of population subdivision using distances between alleles with special reference to microsatellite loci. Genetics 142: 1061-1064.

Miller MP (1997). Tools for Population Genetic Analysis (TFPGA) 1.3: a Windows Program for the Analysis of Allozyme and Molecular Population Genetic Data. Available from http:// bioweb.usu.edu/mpmbio/index.htm.

Nei M (1987). Molecular evolutionary genetics. Columbia University Press: New York.

Nei M, Takezaki M (1996). Reconstruction of phylogenetic trees from microsatellite (STR) loci. Anim Genet 27: 1-16.

Nosil P, Crespi BJ (2006). Ecological divergence promotes the evolution of cryptic reproductive isolation. Proc $R$ Soc London B 273: 991-997.

Ogden R, Thorpe RS (2002). Molecular evidence for ecological speciation in tropical habitats. Proc Natl Acad Sci USA 99: 13612-13615.

Paterson IG, Crispo E, Kinnison MT, Hendry AP, Bentzen P (2005). Characterization of tetranucleotide microsatellite markers in guppy (Poecilia reticulata). Mol Ecol Notes 5: 269-271.

Raymond M, Rousset F (1995). GENEPOP (version 1.2): population genetics software for exact tests and ecumenicism. J Hered 86: 248-249.

Reznick D, Bryga H (1996). Life-history evolution in guppies (Poecilia reticulate: Poeciliidae). V. Genetic basis of parallelism in life histories. Am Nat 147: 339-359.

Reznick D, Butler M, Rodd H (2001). Life-history evolution in guppies. VII. The comparative ecology of high- and lowpredation environments. Am Nat 157: 126-140.

Rosen DE, Bailey RM (1963). The poeciliid fish (Cyprinodontiformes), their structure, zoogeography and systematics. Bull Am Museam Nat Hist 126: 1-176. 
Rousset F (1996). Equilibrium values of measures of population subdivision for stepwise mutation processes. Genetics 142: 1357-1362.

Rundle HD (2002). A test of ecologically dependent postmating isolation between sympatric sticklebacks. Evolution 56: 322-329.

Rundle HD, Nagel L, Boughman JW, Schluter D (2000). Natural selection and parallel speciation in sympatric sticklebacks. Science 287: 306-308.

Rundle HD, Nosil P (2005). Ecological speciation. Ecol Lett 8: 336-352.

Russell ST, Magurran AE (2006). Intrinsic reproductive isolation between Trinidadian populations of the guppy, Poecilia reticulata. I Evol Biol 19: 1294-1303.

Saitou N, Nei M (1987). The neighbor-joining method: a new method for reconstructing phylogenetic trees. Mol Biol Evol 4: 406-425.

Schluter D (2000). The Ecology of Adaptive Radiation. Oxford University Press: Oxford.

Schneider S, Kueffer JJ-M, Roessli D, Excoffier L (1997). ARLEQUIN: An Exploratory Population Genetics Software Environment. Computer software distributed by authors.

Shaw PW, Carvalho GR, Magurran AE, Seghers BH (1991). Population differentiation in Trinidadian guppies (Poecilia reticulata): patterns and problems. J Fish Biol 39: S203-S209.
Shaw PW, Carvalho GR, Magurran AE, Seghers BH (1994). Factors affecting the distribution of genetic variability in the guppy, Poecilia reticulata. J Fish Biol 45: 875-888.

Shaw PW, Carvalho GR, Seghers BH, Magurran AE (1992). Genetic consequences of an artificial introduction of guppies (Poecilia reticulata) in N. Trinidad. Proc $R$ Soc London B 248: 111-116.

Sivasundar A, Bermingham E, Ortí G (2001). Population structure and biogeography of migratory freshwater fishes (Prochilodus: Characiformes) in major South American rivers. Mol Ecol 10: 404-417.

Takezaki N, Nei M (1996). Genetic distances and reconstruction of phylogenetic trees from microsatellite DNA. Genetics 144: 389-399.

Templeton AR (1998). Nested clade analysis of phylogeographic data: testing hypotheses about gene flow and population history. Mol Ecol 7: 381-397.

Ward RD, Woodwark M, Skibinski DOF (1994). A comparison of genetic diversity levels in marine, freshwater, and anadramous fishes. J Fish Biol 44: 213-232.

Weir BS (1979). Inferences about linkage disequilibrium. Biometrics 35: 235-254.

Weir BS, Cockerham CC (1984). Estimating F-statistics for the analysis of population structure. Evolution 38: 1358-1370.

Supplementary Information accompanies the paper on Heredity website (http://www.nature.com/hdy) 